Trab. Ling. Aplic., Campinas, 50(1): 153-167, Jan./Jun. 2011

\title{
AQUISIÇÃO DA PRONÚNCIA: A ENTOAÇÃO EM AFIRMAÇÕES E PERGUNTAS SIM/NÃO**
}

\section{AQUISITION OF PRONUNCIATION: INTONATION IN STATEMENTS AND YES/NO QUESTIONS}

\author{
MARIANNE AKERBERG ${ }^{* *}$
}

\begin{abstract}
RESUMO: Nos últimos anos houve um aumento considerável de pesquisas sobre os aspectos prosódicos na fala e maior consciência da entoação como portadora de significado. Também a abordagem comunicativa supostamente provocou uma mudança no ensino da pronúncia: focalizou os traços suprassegmentais como ritmo e entoação. Este estudo pretende examinar até que ponto os alunos falantes de espanhol da Universidade Nacional Autônoma do México (UNAM) são capazes de distinguir entre os padrões entoacionais de afirmações e perguntas do tipo sim / não em português, dado que as duas línguas apresentam diferenças, sobretudo nas perguntas. Discutem-se também propostas para facilitar a aquisição dos traços supra-segmentais no ensino destas duas línguas próximas.
\end{abstract}

Palavras-chave: Aquisição de padrões entoacionais, afirmações, perguntas sim/não em português

\begin{abstract}
During the last few years there has been an increase in research of prosodic aspects of speech as well as a greater awareness of intonation as conveyor of meaning. The communicative approach is also considered to have provoked a change in the teaching of pronunciation of pronunciation: it focused on suprasegmental features like rhythm and intonation. This study examines to what extent Spanish-speaking students of Portuguese at the Universidad Nacional Autónoma de México (UNAM) are able to distinguish between the intonation patterns of statements and yes / no questions in Portuguese, since the two languages present differences, especially in the questions. Some proposals of how to facilitate the acquisition of suprasegmental features in teaching these two related languages are also discussed.
\end{abstract}

Keywords: Acquisition of intonation patterns, statements, yes / no questions in Portuguese

\section{INTRODUÇÃO}

A entoação — vista como o contorno melódico que acompanha um enunciado — é uma parte importante da língua, mas, diferentemente dos sons que podem ser representados pelos grafemas na língua escrita, não é fácil tomar consciência da melodia que acompanha a articulação dos fonemas. Só é preciso nos lembrarmos da fala monótona de robôs para descobrir quanta informação está incluída nos movimentos entoacionais da fala das pessoas, aos quais, nem sempre, damos a devida atenção. Há muito que é universal na entoação, mas as realizações concretas variam de língua para língua. É, provavelmente,

\footnotetext{
* Agradeço à professora Mônica Nobre, UFRJ, pelas observações pertinentes feitas a este trabalho.

** UNAM-Centro de Enseñanza de Lenguas Extranjeras, México. marianne@servidor.unam.mx
} 
o primeiro traço que a criança adquire e o último que perde o falante nativo de uma língua, por exemplo, por efeito de doença cerebral. A entoação da primeira língua está profundamente enraizada e, muitas vezes, permeia outra língua aprendida resultando numa marca notável de sotaque estrangeiro.

A abordagem comunicativa, que enfatizava o uso da língua como comunicação, deu grande importância à entoação, porque o valor do enunciado depende criticamente da função interativa dentro do discurso (BRAZIL et al 1980, p. ix). Surgiu como uma reação ao método audiolingual e sua ênfase em drills de estruturas gramaticais e de pronúncia descontextualizadas. Os precursores foram os autores que propunham um ensino nocional e funcional (WILKINS, 1977; WIDDOWSON, 1978), seguidos pelos autores da abordagem natural (KRASHEN \& TERRELL, 1983). Estes últimos defendiam a tese de que os adultos podem adquirir uma segunda língua da mesma maneira que as crianças adquirem a primeira língua, em situações comunicativas. Vários partidários desta abordagem declararam que os aspectos prosódicos ou supra-segmentais eram mais importantes do que os segmentos, os fones e os fonemas da L2. ${ }^{1}$ Conforme os preceitos teóricos de Krashen (1981) o ensino explícito de elementos da L2 não leva a uma ‘aquisicão' da língua. Por isso a abordagem comunicativa propunha, no início, que o input compreensível era suficiente para adquirir uma pronúncia razoável. A realidade demonstrou que nem sempre é assim e foram introduzidas novas ideias nos últimos anos de, por exemplo, prestar maior atenção à forma, "focus-on-form"' (LONG, 1991; WILLIAMS, 2005). Contudo, há ainda professores convencidos das afirmações de Krashen de que o aluno adquire a pronúncia escutando 'input' compreensível, e outros, que acham que os alunos precisam de apoio para descobrir os traços relevantes da pronúncia da L2. Daí o interesse em se investigar em que medida os alunos de português como língua estrangeira reconhecem as diferenças de entoação entre sua língua materna, o espanhol, e o português, a segunda língua que estão estudando.

\section{AS FUNÇÕES DA ENTOAÇÃO}

A entoação tem várias funções. Algumas são mais básicas e objetivas e podem até ser consideradas gramaticais, já que ajudam a distinguir enunciados linguísticos como perguntas e declarações ou afirmações. ${ }^{2}$ Em inglês a entoação serve, por exemplo, para

${ }^{1}$ Celce-Murcia et al. (1996, p. 10) comentam a mudança no ensino da pronúncia com a introdução da abordagem comunicativa: as técnicas anteriores centradas nos segmentos foram "flatly rejected on theoretical and practical grounds as being incompatible with teaching language as communication" e os professores e autores de materiais começaram a ensinar "suprasegmental features of language (i.e. rhythm, stress, and intonation) in a discourse context”. D. Brazil, M. Coulthard e C. Johns (1980) também são sintomáticos para a época. Na França, desde antes, havia insistência na prosódia para uma boa pronúncia (cf. Renard, 1970). O material elaborado no México para o ensino de português a falantes de espanhol (da Silva Gomes et al, 1988) continha, principalmente, exercícios de ritmo e entoação.

${ }^{2}$ Nas afirmações constata-se algo e, além disso, não há negação, o que é o caso de todos os exemplos do experimento feito neste estudo. Para isso, existe em português também o sinônimo asserção. Para incluir enunciados que poderiam conter uma negação usamos o termo declaração para abranger tanto statements como declaratives em inglês. 
Trab. Ling. Aplic., Campinas, 50(1), Jan./Jun. 2011

delimitar palavras compostas de frases nominais constituídas por substantivo e adjetivo. Não se trata só da distribuição de acentos nas palavras, mas também da mudança de tons que produz um contorno melódico diferente. Blackbird, um tipo determinado de pássaro, é pronunciado de maneira diferente da expressão black bird, um pássaro negro qualquer, da mesma maneira que greeenhouse significa 'estufa' e uma casa verde se diz green house com outro acento e também com outra entoação.

As funções discursivas e pragmáticas da entoação são um instrumento que o falante tem para indicar, entre outras coisas, se terminou o seu discurso ou se vai continuá-lo: Comprei tomate, alface, cebola, se terminar com entoação ascendente, indicará que o falante ainda comprou alguma outra coisa, mas, se proferido com entoação descendente, dará a entender para o interlocutor que foi tudo o que comprou e que, além disso, terminou o seu turno conversacional. Outra função da entoação é a de assinalar a informação conhecida, que é normalmente expressa em um tom baixo, e qual é a informação nova, indicada, em geral, em um tom mais alto. Além disso, a entoação pode dar indícios do estado de ânimo, das emoções e das atitudes do falante. Prieto (2003, p. 14), por exemplo, menciona três funções: a função expressiva, a função focalizadora e a função demarcativa. Halliday (1970, p. 22) propõe que o sistema de tons, ingrediente principal da entoação, serve para indicar contrastes na fala. A seleção entoacional se relaciona com o modo ( $m o o d)$, a modalidade (modality) e a clave (key) no discurso. O modo determina quando se trata de afirmações, perguntas ou ordens; a modalidade indica possibilidade, probabilidade, validade ou relevância do enunciado - expressas, também, com formas de verbos modais. A clave (key) seria portadora da atitude do falante, por exemplo, se é cortês, rude, ou indiferente. Chun (2002, p. xiv) ainda propõe quatro funções diferentes para a entoação: as gramaticais, que ajudam a distinguir perguntas de declarações, e que segmentam o discurso em palavras, frases e orações; as atitudinais ou afetivas, que expressam emoções, atitudes e intenções; as discursivas, que transmitem significados pragmáticos, proporcionam coesão no discurso, dão indícios de mudança de turno (turn-taking) e que distinguem diferentes modos discursivos; e, finalmente, as funções sociolinguísticas, que servem para indicar o papel do status do falante, e ajudam no cumprimento de regras sociais de cortesia. Vemos que todas as classificações abrigam muitos aspectos comuns, mas, de um modo geral, podemos distinguir entre funções mais linguísticas e possíveis de sistematizar e classificar, e outras mais abertas a variações individuais.

O nosso objeto de estudo são as funções mais objetivas e facilmente reconhecidas pelos falantes, as também consideradas gramaticais, que distinguem, por exemplo, as afirmações - declarações, asserções — das perguntas. Há perguntas de diferentes tipos, mas, aqui, interessam-nos, apenas, as de resposta sim / não.

Embora se diga que o fato de marcar perguntas através da entoação seja um dado universal e que há tendências fortes de elevação do tom no final da pergunta na maioria das línguas, há diferenças entre os padrões entoacionais do espanhol e os do português. Isso pode causar problemas para o aluno falante de espanhol, tanto na compreensão, quanto na produção linguística da L2 por interferências dos padrões de entoação de sua L1. 


\section{OS PADRÕES ENTOACIONAIS DO ESPANHOL E DO PORTUGUÊS}

Espanhol e português são línguas muito próximas, ambas da família de línguas românicas, mas com diferenças salientes de entoação, sobretudo nas perguntas sim / não. Como pode haver ligeiras variações regionais, é preciso deixar claro que, aqui, vamos estudar o português do Brasil — ressalvados falares do Sul e do Nordeste -, e o espanhol do México - típico da cidade do México e dos meios de comunicação desse país.

No espanhol, o tom vai subindo e termina com tom alto na pergunta. No português do Brasil o tom sobe e depois desce. Se compararmos as perguntas com as afirmações os esquemas seriam:

Espanhol: $\quad$ El es médico. ${ }^{3}$

$$
\mathrm{H}+\mathrm{L} * \mathrm{~L} \%
$$

Português: Ele é médico.

$$
\mathrm{H}+\mathrm{L} * \mathrm{~L} \%
$$

¿El es médico?

$$
\mathrm{L}+\mathrm{H}^{*} \mathrm{H} \%
$$

Ele é médico?

(H) $\mathrm{L}+\mathrm{H}^{*} \mathrm{~L} \%$

No final do enunciado, neste caso, na palavra médico - a expressão em que se produz o maior movimento entoacional - estão os sinais diacríticos do modelo métrico autossegmental. ${ }^{4}$ Os significados das maiúsculas são: H (high) tom alto, L (low) tom baixo;* indica a sílaba tônica, e \% fim da unidade de entoação. A combinação de L com $\mathrm{H}$ resulta em uma entoação ascendente, e a combinação H com L em uma entoação descendente

Tanto no português brasileiro, quanto no espanhol do México, a afirmação mantém um nível baixo de curvas melódicas. Na pergunta sim / não o tom sobe na última sílaba tônica nas duas línguas. Todavia, enquanto no espanhol o tom se mantém em alto, no português há uma queda notável na postônica. Outra diferença entre as duas línguas é que, na pergunta em português, o início do enunciado normalmente tem um tom mais alto, fato registrado por Moraes (1998). ${ }^{5}$ Em português, há a possibilidade de a pergunta terminar com tom alto se houver uma palavra oxítona no final do enunciado, pois assim não há sílaba postônica que possa portar a queda do tom: Ele sofreu um ataque do coração? Em espanhol, a sílaba tônica no final do enunciado tem tom alto na pergunta $\operatorname{sim} /$ não, e a sílaba postônica normalmente mantém o tom alto. $\mathrm{O}$ aluno hispanofalante que aprende português pode interpretar a queda do tom na pergunta em português como indicadora de afirmação e a intenção comunicativa é, desse modo, prejudicada. Os alunos, algumas vezes, confundem-se ao interpretarem estes padrões entoacionais. Este problema foi um dos motivadores desta investigação.

${ }^{3} \mathrm{O}$ exemplo em espanhol, com o uso explícito do pronome pessoal, tem uma ligeira ênfase e por isso não é totalmente equivalente ao exemplo em português, mas como o interesse está centrado no final do enunciado, esse fator não importa para a finalidade do estudo.

${ }^{4}$ Descricão proposta por Pierrehumbert (1980) e usada por, entre outros, Hualde (2003).

${ }^{5}$ Diz a propósito destas duas modalidades em português: "a) the initial pitch of the yes/no question is slightly higher than in the case of a declarative; b) on the other hand, the final pretonic of a yes/no question is lower than the final pretonic of a declarative, thus creating a greater contrast with the final tone." (MORAES, 1998, p.184) 
Para que se possam observar as diferenças mais claramente inserimos alguns gráficos gerados pelo programa computacional $\mathrm{PRAAT}^{6}$ com exemplos tanto do espanhol quanto do português. Os primeiros dois exemplos em espanhol foram gravados especificamente para que se pudesse compará-los com os mesmos exemplos em português tomados do instrumento da pesquisa (Anexo 1):

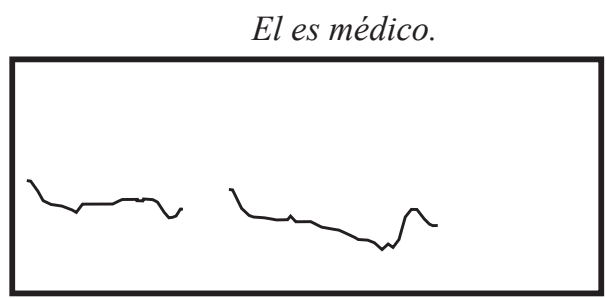

Gráfico 1

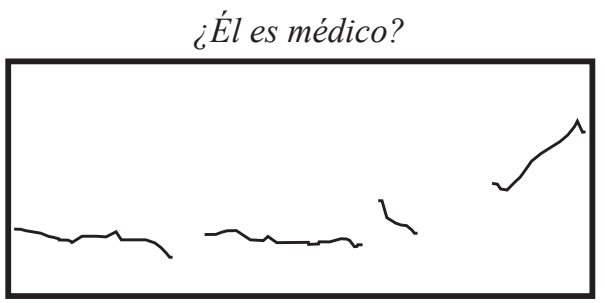

Gráfico 2

No exemplo da frase afirmativa (Gráfico 1) só se nota um pequeno movimento no verbo ser e outro no fim do enunciado na sílaba tônica de médico. A pergunta tem uma subida muito acentuada no final, o que indica o tom alto (Gráfico 2). A queda ligeira no final da pergunta em espanhol é atribuída a um ensurdecimento de vogal final de médico neste exemplo, uma variação individual da falante em questão. O contorno melódico da pergunta, que foi gravada por uma informante mexicana, corresponde a vários dos resultados obtidos por Avila (2004).

Nos exemplos do português — assinalados com os números que tinham os reativos no experimento — os movimentos são diferentes:

Ele é médico.

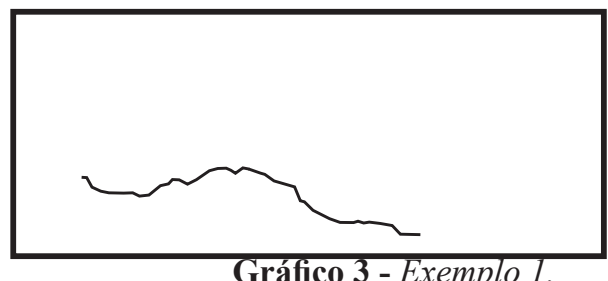

Ele é médico?



Grático 4 - Exemplo 16.

Na afirmação, há uma subida ligeira na forma verbal é e depois o tom vai descendo no resto do enunciado. Na pergunta, há uma subida forte no início, em seguida uma descida para logo subir na sílaba mé- de médico e, finalmente, cair nas sílabas átonas -dico. O comportamento típico da pergunta em português são estes dois movimentos fortes, no início e no final, e com uma queda no final, quando em muitas outras línguas ocidentais a pergunta, normalmente, fica num tom alto, sem queda.

${ }^{6}$ PRAAT é um software para análise de fala desenvolvido por Paul Boersma e David Weenink, da Universidade de Amsterdam, disponível gratuitamente na página www.praat.org. 


\section{OBJETIVOS DO PRESENTE ESTUDO}

Nesta pesquisa pretendemos observar até que ponto os alunos hispanofalantes de português são capazes de distinguir entre as afirmações e as perguntas de tipo sim / não em português. Como se mencionou anteriormente, a queda do tom no final da pergunta em português pode ser interpretada como uma afirmação em espanhol.

As perguntas principais desta investigação são:

a) Será possível encontrar uma progressão natural na capacidade de distinguir entre afirmação e pergunta, o que significaria, com o avanço dos estudos, os alunos tendem a adquirir essa distinção importante?

b) O número de sílabas dos enunciados interfere na identificação do foco da mensagem? Por exemplo, quanto maior o número de sílabas, mais difícil será descobrir o foco prosódico no final do enunciado; por outro lado, quanto menos sílabas, mais fácil será interpretar o significado da entoação?

Nossas hipóteses de trabalho são:

1. Há progresso com o tempo. Os alunos melhoram significativamente quanto mais se intensifica o contato com a língua. Os alunos dos níveis iniciais cometem mais erros do que os alunos avançados.

2. Reconhecer o padrão entoacional das perguntas é mais difícil do que reconhecer o padrão das afirmações.

3. Em cada grupo, sempre há alunos com maior aptidão no sentido de Carroll (1981) para descobrir essas diferenças, ${ }^{7}$ independentemente do nível.

4. Os exemplos mais difíceis de serem detectados são os que contêm mais palavras e mais sílabas, já que a curva melódica típica da pergunta com tom mais alto no início não se relaciona tão facilmente com o foco prosódico no final do enunciado.

\section{DESCRIÇÃO DO EXPERIMENTO}

Fez-se uma gravação de 15 enunciados com uma falante nativa de português do Brasil, uma vez com entoação de afirmação e outra vez com a de pergunta sim / não o que resultou numa lista de 30 elicitações que foram posteriormente embaralhadas. (Anexo 1)

Escutaram a gravação um total de 119 alunos de português, todos hispanofalantes, estudantes de seis níveis ${ }^{8}$ — cada nível equivalente a um semestre. Após a escuta da gravação (por duas vezes, de modo a que se minimizassem possíveis problemas de entendimento), os alunos deveriam marcar, num quadro com números para cada exemplo (de 1 a 30), se os enunciados eram uma afirmação ou pergunta. Vale assinalar aqui que, antes da realização do experimento, já se tinha feito um teste-piloto com vários falantes nativos brasileiros que obtiveram $100 \%$ de acertos. Do mesmo modo, fez-se esse experimento prévio com cinco professores mexicanos que tiveram muito poucos erros, apenas $0.4 \%$ em média.

\footnotetext{
${ }^{7}$ Um dos quatro fatores que constituem a base para a aptidão, segundo Carroll (1981, p. 105), é a capacidade de analizar os sons escutados, de maneira que possam ser retidos (phonemic coding ability).

${ }^{8}$ Eram 11 grupos no total, porque havia, em alguns casos, vários alunos de cada nível. 


\section{RESULTADOS EM NÚMEROS}

Os resultados dos grupos ${ }^{9}$ de alunos que deveriam distinguir as perguntas das afirmações foram os seguintes:

Tabela 1 - Média de desvios por grupo.

\begin{tabular}{|c|c|c|}
\hline Grupo & No. alunos & Média desvios \\
\hline 1.1 & 15 & $7,53 \%$ \\
\hline 1.2 & 12 & $8,58 \%$ \\
\hline 1.3 & 13 & $4,07 \%$ \\
\hline 2.1 & 20 & $3,9 \%$ \\
\hline 2.2 & 5 & $6,2 \%$ \\
\hline $\mathbf{3 . 1}$ & $\mathbf{1 3}$ & $\mathbf{2 , 9 2 \%}$ \\
\hline 3.2 & 7 & $6,42 \%$ \\
\hline 4.1 & 10 & $8,1 \%$ \\
\hline $\mathbf{5 . 1}$ & $\mathbf{9}$ & $\mathbf{2 , 8 8 \%}$ \\
\hline 6.1 & 10 & $3,8 \%$ \\
\hline 6.2 & 5 & $4,4 \%$ \\
\hline Total & $\mathbf{1 1 9}$ & \\
\hline & \multicolumn{2}{|}{} \\
\hline
\end{tabular}

A Tabela 1 permite observar que não é necessariamente o tempo de estudo do aluno que determinará um bom desempenho no teste proposto. Os melhores resultados, indicados em negrito, não correspondem aos dois grupos do último nível. Por exemplo, o grupo 1.3, de principiantes, apresentou apenas $4 \%$ de desvios do que se esperava como resposta, muito perto da média dos grupos de sexto nível, que obteve resultados de 3,8\% e 4,4\% respectivamente. Há grupos que têm praticamente o dobro do percentual de respostas desviantes em relação a outros grupos do mesmo nível. Comparem-se, por exemplo, os resultados dos grupos 2.1 e 2.2, 3.1 e 3.2 .

Na tabela seguinte vemos as porcentagens dos desvios relacionados à resposta depois de feita a escuta dos enunciados. Cada enunciado foi elicitado ora como uma afirmação ora como uma pergunta. Observa-se que as reações às perguntas levaram a um maior número de desvios do que as reações às afirmações. Mesmo assim, ainda há casos como os de números 17 e 28 que se constituíram numa contra-expectativa em relação ao que se acaba de dizer. Em geral, as perguntas levam a mais erros do que as afirmações, mas há algumas exceções como os casos 17 e 28 que são as afirmações com mais erros.

${ }^{9}$ A notação da numeração dos grupos indica, com o primeiro algarismo, o nível e com o segundo algarismo, o grupo. Assim os grupos 1.1 a 1.3 são do primeiro nível, ou seja, do primeiro semestre, e os grupos 6.1 e 6.2 do sexto nível ou do sexto semestre. Os grupos destacados representam os alunos que melhores resultados obtiveram. 
AKERBEERG - Aquisição da pronúncia: a entoação em afirmações...

Tabela 2 - Percentuais de desvio de todos os exemplos.

\begin{tabular}{|l|l|l|l|l|}
\hline No. & No. & Exemplo & $\mathbf{\%}$ Afirm. & \% Perg. \\
\hline 1. & $16 ?$ & Ele é médico & 5 & 16,4 \\
\hline 17. & $2 ?$ & Tem tempo agora & $\mathbf{5 1 , 5}$ & 13,5 \\
\hline 18. & $3 ?$ & Há outras pessoas em casa & 25,3 & 27,3 \\
\hline 4. & $19 ?$ & As meninas vão à escola à tarde & 7,7 & 16,5 \\
\hline 5. & $20 ?$ & O pai cuida das crianças & 14,6 & 9,5 \\
\hline 21. & $6 ?$ & Esta casa tem duas entradas & 10,2 & $\mathbf{7 6 , 7}$ \\
\hline 7. & $22 ?$ & O apartamento é muito caro & 8,2 & 25,4 \\
\hline 23. & $8 ?$ & Hoje é sexta-feira & 6,8 & 14,3 \\
\hline 9. & $24 ?$ & Ele gastou todo o dinheiro & 10,9 & 28,9 \\
\hline 25. & $10 ?$ & Este lugar está ocupado & 19,8 & 4,6 \\
\hline 11. & $26 ?$ & Ele fala muito & 3,2 & 27,3 \\
\hline 12. & $27 ?$ & Na rua tinha muita gente & 6,2 & 31,5 \\
\hline 28. & $13 ?$ & Você gosta de ir à praia & $\mathbf{2 7 , 3}$ & 3,4 \\
\hline 14. & $29 ?$ & Deixou toda a fortuna para os sobrinhos & 2,3 & 17,0 \\
\hline 15. & $30 ?$ & Sofreu um ataque do coração & 4,6 & 3,6 \\
\hline
\end{tabular}

Uma pergunta específica, o exemplo 6, resultou muito difícil de identificar. Na discussão dos resultados trataremos de encontrar uma explicação.

\section{DISCUSSÃO DOS RESULTADOS}

Em relação às hipóteses, pode-se, com base no experimento realizado, afirmar o seguinte: a primeira hipótese (os alunos dos níveis iniciais cometem mais erros do que os alunos dos níveis avançados), não se confirmou. Não houve melhora de desempenho determinada pelo progresso do nível do aluno. Houve grupos de alunos de nível avançado que cometeram mais desvios nas respostas esperadas do que os principiantes.

A segunda hipótese (reconhecer o padrão entoacional das perguntas é mais difícil do que reconhecer o padrão das afirmações) se confirmou: dos exemplos que apresentavam o maior número de desvios do que se esperava - um total de nove com mais de $25 \%$ de desvios - seis eram de perguntas e três de afirmações. Assim, confirmou-se a ideia inicial de que os alunos têm maiores problemas com a identificação das perguntas.

A terceira hipótese (em cada grupo sempre há alunos com maior aptidão para descobrir essas diferenças independentemente do nível) também se confirmou. Poucos alunos em todos os grupos — entre principiantes, médios e avançados — cometeram zero desvios na tentativa de identificar as diferenças entre as entoações de pergunta e de afirmação. ${ }^{10}$ Por outro lado, também houve alunos em todos os níveis que se equivocaram nas respostas de cerca de metade dos exemplos.

O fator número de sílabas dos exemplos, a quarta hipótese, não parece ter exercido influência. A hipótese era a de que seria mais fácil a identificação das perguntas e das afirmações que contivessem menos sílabas, ou inversamente, a de que haveria maior problema para os alunos distinguirem os enunciados com maior número de sílabas.

\footnotetext{
${ }^{10}$ Um aluno no 1 o nível, outro no $3^{\circ}$ nível e dois no $6^{\circ}$ nível.
} 
Houve exemplos com 12 sílabas, que não representaram nenhum obstáculo para a testagem, enquanto que exemplos contendo seis sílabas levaram a uma taxa com mais de $30 \%$ de desvios.

Qual é a explicação para as diferenças entre os grupos? Tudo indica que o fator mais importante para explicá-las seria o desempenho do professor e o seu interesse pelo ensino da pronúncia em suas aulas. Em entrevistas feitas com os professores dos grupos que obtiveram melhores resultados, eles mencionaram que o ensino de pronúncia era muito importante e que era preciso chamar a atenção do aluno tanto para a entoação quanto para a articulação fonética em geral. Havia dois professores falantes nativos de português e um professor mexicano entre eles. Várias entrevistas com alunos confirmaram as observações feitas pelos professores.

Fazendo-se a análise dos exemplos que apresentaram um alto número de desvios, foi importante observar o modo como outros fatores interferiam na interpretação dos enunciados da testagem. Os casos dos desvios mais frequentes em que os alunos fizeram interpretação de pergunta em lugar de afirmação — o que não era o esperado, tendo em vista que a expectativa era a de que eles se equivocariam principalmente com a entoação de pergunta em português - ocorreram com os exemplos de afirmação Tem tempo agora (Ex. 17) e Você gosta de ir à praia (Ex. 28). Justificam-se esses desvios face à pouca probabilidade de ocorrência dessas estruturas como afirmação. O mais frequente é de encontrá-las em perguntas. O verbo gostar, com pronome você, usa-se tipicamente em perguntas, não para afirmar ou fazer constatações. Dessa maneira, vê-se que há interação entre o conteúdo semântico-lexical do enunciado com a informação que porta a entoação. Quando há insegurança de parte dos estudantes para interpretar o contorno entoacional, eles usam a informação contida em outros elementos linguísticos.

Para explicar alguns casos de percentual elevado de desvios, fizemos uma análise acústica do exemplo 6 -Esta casa tem duas entradas?-(Gráfico 5), aparentemente o de entendimento mais difícil para todos os alunos.

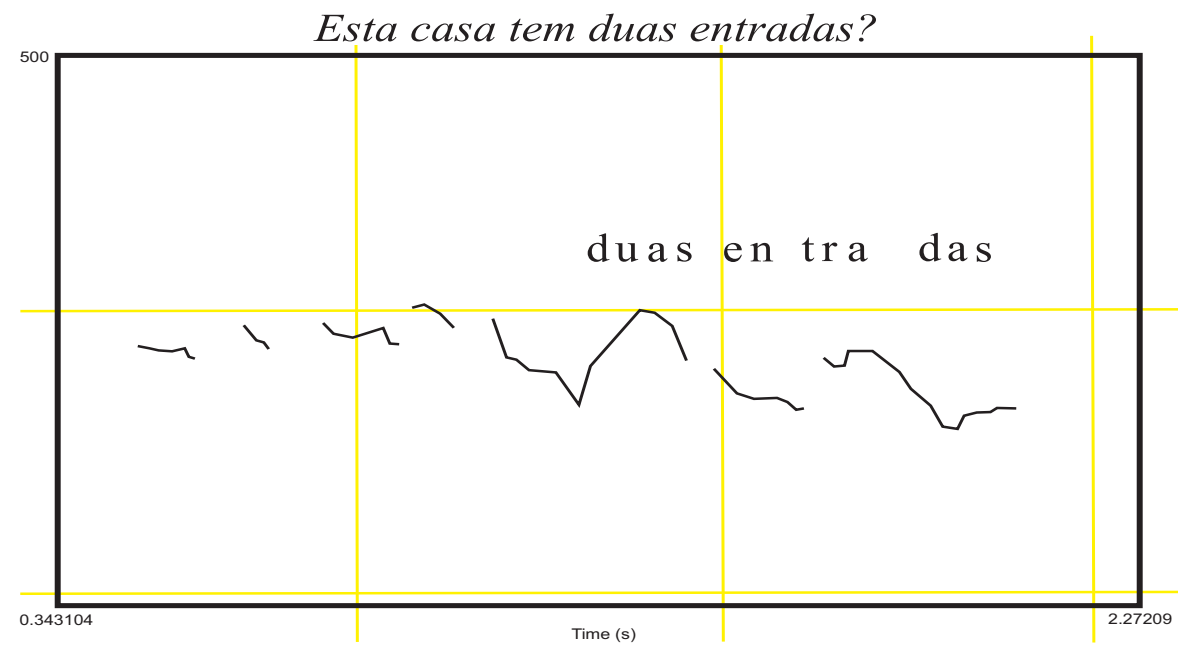

Gráfico 5 - Exemplo 6. 
Neste exemplo, que provocou muitos problemas de interpretação, em alguns grupos chegando mesmo a quase $100 \%$ de erros, há duas subidas fortes de tom, na primeira sílaba de duas e na sílaba -tra- da última palavra, com uma queda final. O mais comum teria sido uma subida na primeira palavra casa e depois na sílaba acentuada de entradas. Parece que os movimentos entoacionais na última palavra foram comprometidos pela subida em duas e assim foi difícil interpretar o enunciado como pergunta. Comparamos o enunciado com a sua contraparte afirmativa:

Esta casa tem duas entradas.

Esta casa tem duas entradas.

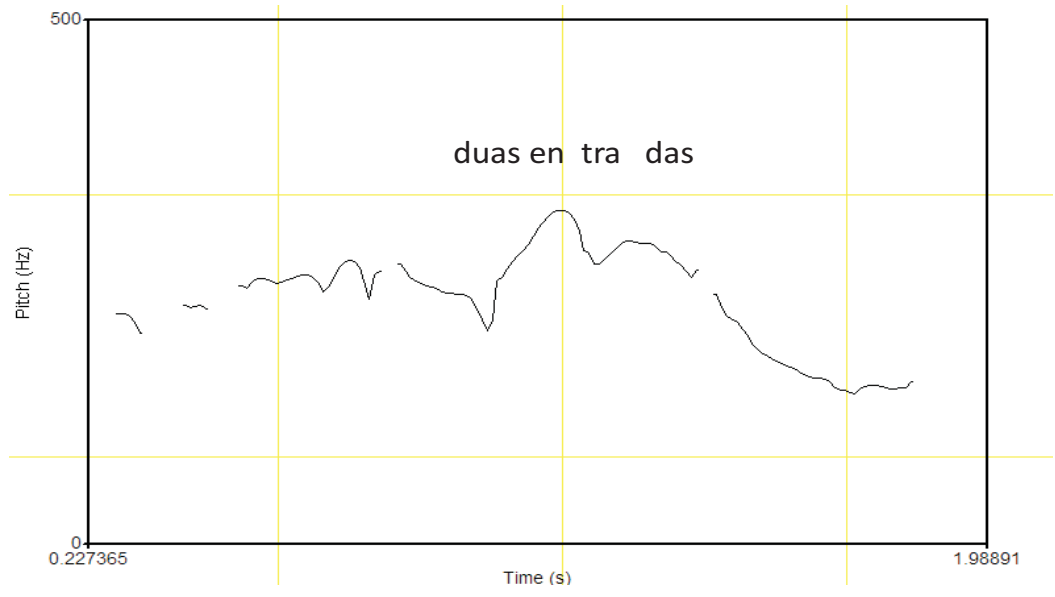

Gráfico 6 - Exemplo 21.

Na afirmação só há uma subida na palavra duas e depois um descida nítida. Esse enunciado não representou problema para os alunos.

Se compararmos com outros exemplos de aproximadamente o mesmo número de sílabas, vemos que neles a distinção é um pouco mais clara. 
O apartamento é muito caro.

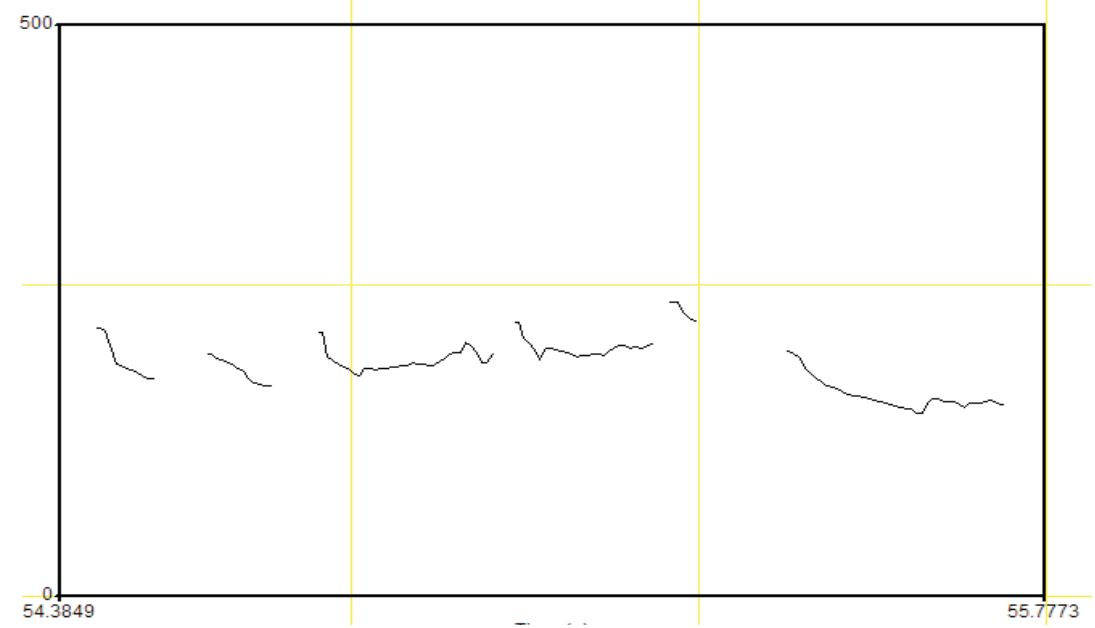

Gráfico 7 - Exemplo 7.

No Gráfico 7 nota-se pouco movimento tonal e tudo termina num tom baixo, o que indica uma declaração neutra típica nos moldes de Moraes (1998).

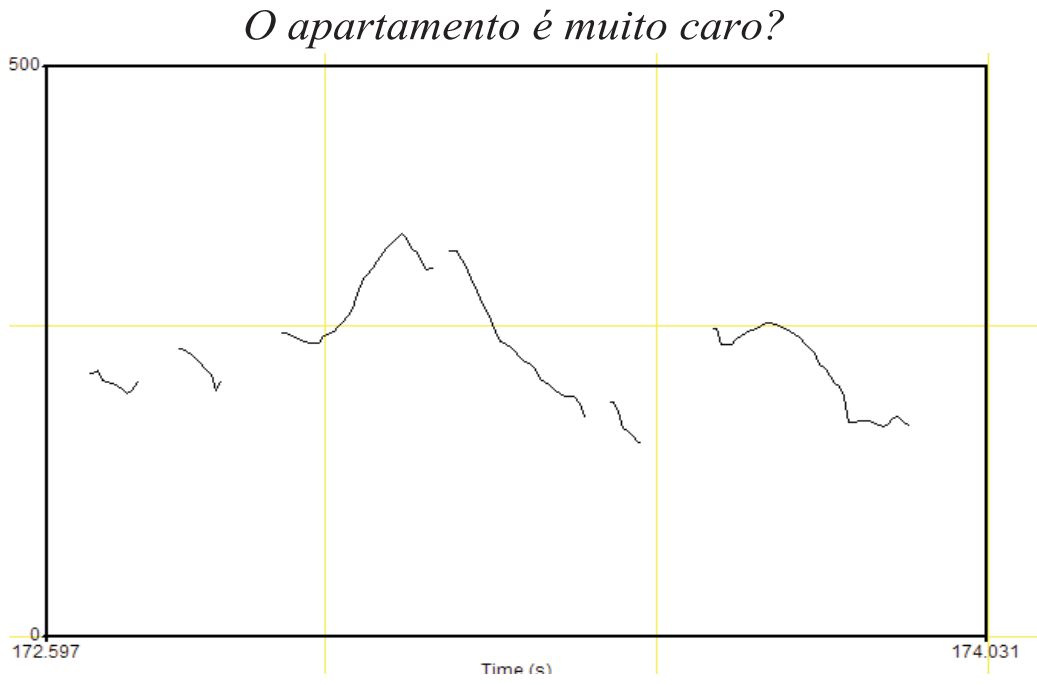

Gráfico 8 - Exemplo 22. 
No exemplo da pergunta do Gráfico 8, vemos o movimento típico de subida inicial na primeira palavra acentuada e uma subida na última sílaba acentuada.

Fazendo-se as análises acústicas das perguntas - que foram os enunciados que representaram o problema principal e motivador desta pesquisa - observou-se que em todas houve as características típicas de perguntas, conforme previsto em Moraes (1998): um início mais alto do que na afirmação e uma subida forte seguida por uma queda no núcleo final.

Os exemplos 15 e 30 do enunciado Sofreu um ataque do coração, elicitado como afirmação, no exemplo 15, e como pergunta, no exemplo 30, foram interpretados adequadamente pela grande maioria dos alunos. A subida do tom, na última sílaba tônica da pergunta, coincide muito bem com a entoação canônica do espanhol, tendo em vista que, nessa língua, é remotíssima a possibilidade de uma queda na sílaba final de palavras oxítonas em perguntas.

\section{CONCLUSÕES E RECOMENDAÇÕES PARA A SALA DE AULA}

Com as abordagens comunicativas e discursivas de ensino de línguas estrangeiras, o interesse é dirigido e focalizado no conteúdo da mensagem. Para uma interpretação adequada, a entoação é muito importante, já que proporciona mais informação. Contudo, os resultados deste estudo revelam que nem todos os alunos descobrem só com o input, as particularidades da entoação do português, como propunha a abordagem comunicativa em sua fase inicial.

É necessário fazer com que os alunos prestem atenção às características especiais que tem a entoação nas duas línguas. A atenção, no sentido de Schmidt (2001), é uma condição para a aquisição. ${ }^{11}$ Vimos que um fator muito importante é o professor e o tempo que dedica a guiar os alunos a descobrirem essas diferenças. É uma atividade de foco na forma (LONG, 1991; DOUGHTY \&WILLIAMS, 1998; WILLIAMS, 2005) que é essencial para a aquisição.

O primeiro passo, que deveria ser dado, seria o de sensibilizar o aluno para as funções da entoação em geral, com exercícios de, por exemplo, frases curtas ou até de palavras monossilábicas (hoje, não), pronunciadas com diferentes entoações para indicar surpresa, incredulidade, raiva, acordo neutro. Sugere-se, também, usarem-se exemplos de ênfase contrastiva nos quais a mesma frase com diferentes prominências e curvas entoacionais, responde a perguntas diferentes: ELE chegou às duas horas (Pergunta: Quem chegou?), Ele CHEGOU às duas horas (Pergunta: Foi embora às duas horas?) etc. Uma vez feita essa sensibilização, introduzem-se mais exemplos e exercícios de discriminação, por exemplo, para que sejam distinguidas perguntas de declarações. Provavelmente, será suficiente realizar os exercícios no nível da percepção auditiva. Com essa chamada de atenção, os alunos começariam a notar as diferenças desejadas entre perguntas e afirmações, o que seria uma condição para a aquisição.

${ }^{11}$ Schmidt propõe que a atenção é o acesso para a conscientização (awareness) e a aprendizagem e que, além disso, "SLA is largely driven by what learners pay attention to and notice in target language input and what they understand the significance of noticed input to be" (2001, p. 6). 
Ainda que se admita que os contornos entoacionais dos enunciados do português e do espanhol tenham muita variação regional e individual, é preciso que se tenha em mente que as diferenças entre os padrões de perguntas e afirmações nas duas línguas são sistemáticas e possíveis de serem ensinados aos alunos. Por isso, recomenda-se fazê-lo. Ao mesmo tempo, também seria aconselhável dedicar tempo e esforço ao ritmo — visto por alguns autores como incluído na entoação, segundo a definição ampla do termo, feita por Hirst \& Di Cristo (1998, p. 4-5) — já que tanto o espanhol, quanto o português apresentam, cada qual, um sistema prosódico diferente. ${ }^{12} \mathrm{O}$ ritmo e a entoação se complementam e favorecem a inteligibilidade dos enunciados.

Também é possível que, como propõem vários pesquisadores, ${ }^{13}$ uma vez que o aluno tenha tomado consciência dos fenômenos suprassegmentais ou prosódicos básicos, a aquisição dos fonemas passe a ser mais fácil. Espera-se, da mesma maneira, que este estudo possa contribuir para conscientizar professores da importância que eles próprios têm durante as suas atuações nas aulas, ajudando seus alunos a desempenharem melhor.

\section{REFERÊNCIAS BIBLIOGRÁFICAS}

AVILA HERNÁNDEZ, S. (2004). La entonación del enunciado interrogativo en el español de la ciudad de México. In: HERRERA. E. \& P. MARTÍN BUTRAGUEÑO (orgs.) La tonía: dimensiones fonéticas y fonológicas. México: El Colegio de México, p. 331-355.

BRAZIL, D.; COULTHARD, M. \& JOHNS, C. (1980). Discourse intonation and language teaching. London: Longman.

CARROLL, J. B. (1981). Twenty-five years of research on foreign language aptitude. In: K.C. DILLER (ed.). Individual differences \& universals in language learning aptitude. Rowley, Mass.: Newbury House, $\mathrm{p}$. 83-118.

CELCE-MURCIA, M.; BRINTON, D. M. \& GOODWIN, J. M. (1996). Teaching pronunciation. A reference for teachers of English to speakers of other Languages. Cambridge: Cambridge University Press.

CHUN, D.M. (2002). Discourse intonation in L2. From theory to practice. Amsterdam: J. Benjamins.

DA SILVA GOMES, M. H. et al. (1988). Curso ativo de português. México: CELE/UNAM.

DOUGHTY, C. \& WILLIAMS, J. (orgs.) (1998). Focus on form in classroom second language acquisition. Cambridge: Cambridge University Press.

GILBERT, J. B. (1980). Prosodic development: Some pilot studies. In: R.C. SCARCELLA \& S.D. KRASHEN (orgs.) Research in second language Acquisition. Selected papers of the Los Angeles Second Language Acquisition Research Forum, Rowley, Massachusetts: Newbury House, p. 110-117.

${ }^{12}$ Em termos gerais, o espanhol tem o ritmo silábico (syllable-timed) - mais ou menos a mesma duração ou tempo para cada sílaba - e o português o ritmo acentual (stress-timed) no qual a sílaba tônica tem maior duração, e as sílabas átonas ficam reduzidas, embora exista alguma crítica contra esta visão um pouco simplificada.

${ }^{13}$ Esta ideia foi proposta, entre outros, pelos autores Gubérina e Rivenc quando, nos anos 60, elaboraram um material para ensinar francês com o método verbo-tonal estruturado. A aplicação deste método para o ensino da pronúncia foi explicitada no livro de Renard (1979). Mais tarde, Judy Gilbert (1980, 1984, 2008) tem sido uma defensora da importância da prosódia no ensino da pronúncia. 
AKERBEERG - Aquisição da pronúncia: a entoação em afirmações...

GILBERT, J. B. (1984). Clear speech: Pronunciation and listening in American English. Cambridge: Cambridge University Press.

. (2008). Teaching pronunciation. Using the prosody pyramid. Cambridge: Cambridge University Press.

GUBÉRINA, P. \& RIVENC, P. (1961). Voix et images de France. Paris: Didier.

HALLIDAY, M.A.K. (1970). A course in spoken English: Intonation. London: Oxford University Press.

HERRERA. E. \& MARTÍN BUTRAGUEÑO, P. (orgs.) (2004). La tonia: dimensiones fonéticas y fonológicas, México: El Colegio de México.

HIRST, D. \& DI CRISTO, A. (orgs.) (1998). Intonation systems. Cambridge: Cambridge University Press.

HUALDE, J. I. (2003). El modelo métrico y autosegmental. In: Prieto, P. (org.), Teorías de la entonación, p. $155-184$.

KRASHEN, S. (1981). Second language acquisition and second language learning. Oxford: Pergamon.

KRASHEN, S. \& TERRELL, T. (1983). The natural approach: Language acquisition in the classroom. Oxford: Pergamon Press

LONG, M. H. (1991). Focus on form: A design feature in language teaching methodology. In: K. de Bot, R. Ginsberg \& C. Kramsch (eds.). Foreign language research in crosscultural perspective. Amsterdam: J. Benjamins, p. 39-52.

MORAES, J. A. de (1998). Intonation in Brazilian Portuguese. In: D. Hirst \& A. Di Cristo (orgs.) Intonation Systems, p. 179-194.

PIERREHUMBERT, J. (1980). The phonology and phonetics of English intonation. MIT.

PRIETO, P. (org.) (2003). Teorías de la entonación. Barcelona: Ariel.

RENARD, P. (1979). Introduction à la méthode verbo-tonale de correction phonétique. Paris: Didier.

SCHMIDT, R. (2001). Attention. In P. ROBINSON, Cognition and second language instruction. Cambridge: Cambridge University Press, p. 3-32.

WIDDOWSON, H. G. (1978). Teaching language as communication. Oxford: Oxford University Press.

WILKINS, D.A. (1977). Notional syllabuses: A taxonomy and its relevance to foreign languag curriculum development. Oxford: Oxford University Press.

WILLIAMS, J. (2005). Form-focused instruction. In E. Hinkel (ed.) Handbook of research in second language teaching and learning. Mahwah, N. J.: L. Erlbaum.

Recebido: 09/09/2009

Aceito: 27/01/2011 
Anexo 1

\section{AFIRMACÕES E PERGUNTAS SIM/NÃO}

1. Ele é médico.

2.Tem tempo agora?

3. Há outras pessoas em casa?

4. As meninas vão à escola à tarde.

5. O pai cuida das crianças.

6. Esta casa tem duas entradas?

7. O apartamento é muito caro.

8. Hoje é sexta-feira?

9. Ele gastou todo o dinheiro.

10. Este lugar está ocupado?

11. Ela fala muito.

12. Na rua tinha muita gente.

13. Você gosta de ir à praia?

14. Deixou toda a fortuna para os sobrinhos.

15. Sofreu um ataque do coração.

16. Ele é médico?

17. Tem tempo agora.

18. Há outras pessoas em casa.

19. As meninas vão à escola à tarde?

20. O pai cuida das crianças?

21. Esta casa tem duas entradas.

22. O apartamento é muito caro?

23. Hoje é sexta-feira.

24. Ele gastou todo o dinheiro?

25. Este lugar está ocupado.

26. Ela fala muito?

27. Na rua tinha muita gente?

28. Você gosta de ir à praia.

29. Deixou toda a fortuna para os sobrinhos?

30. Sofreu um ataque do coração? 
